\title{
Structure of Difructose Anhydride II
}

\author{
By Emma J. McDonald and Anne L. Turcotte
}

\begin{abstract}
The structure of difructose anhydride II is shown to be $2,1^{\prime}-4,2^{\prime}$-difructofuranose. 3,4,6-Trimethylfructose has been identified as one of the hydrolysis products of hexamethyl difructose anhydride II. This has been accomplished by a chromatographic separation with subsequent identification of 3,4,6-trimethylglucosazone.
\end{abstract}

\section{Introduction}

The difructose anhydrides include four welldefined crystalline sugars. Diheterolevulosan was first prepared by Pictet and Chavan $[1]^{1}$ by the action of concentrated hydrochloric acid on fructose at $0^{\circ} \mathrm{C}$. This sugar is a difructopyranose in which carbon atoms 1 and 2 of each fructose residue are joined to form a dioxane ring. The other members $[2,3]$ of this group are designated difructose anhydrides I, II, and III, all of which are found in the reaction product when inulin is hydrolyzed with acid. Difructose anhydride I has been shown [4] to be a difructofuranose in which the two fructose residues are joined as they are in diheterolevulosan. Difructose anhydride III [5] has been identified as difructofuranose in which carbon atoms 1 and 2 of one fructose residue unite with carbons 2 and 3 of the other, again forming a dioxane ring. Previous work, as will be briefly reviewed, has indicated the structure of difructose anhydride II which we now show conclusively to be $2,1^{\prime}-4,2^{\prime}$-difructofuranose.

McDonald and Jackson [5] hydrolyzed the hexamethyl derivative of difructose anhydride II and found that the specific rotation of the hydrolysis product in aqueous solution was approximately +25 degrees. This positive rotation indi-

\footnotetext{
1 Figures in brackets indicate the literature references at the end of this paper.
}

cated the presence of fructofuranose rather than pyranose derivatives. In the latter case one would expect a negative rotation. Upon treatment with phenylhydrazine, an oil resulted that could not be identified.

In a later investigation McDonald and Jackson [6] studied the reaction of the difructose anhydrides with periodic acid. In keeping with their known structures, difructose anhydrides I and III and diheterolevulosan consumed, respectively, 2, 1 , and 4 moles of acid per molecule of sugar. One mole of periodic acid reacted with each molecule of difructose anhydride II.

In order to verify the position of the rings in the fructose residues of this sugar, the following procedure has been carried out: Hexamethyl difructose anhydride II was hydrolyzed in hydrochloric acid solution and the resulting trimethylfructose mixture converted to the corresponding methylfructosides. Further methylation, followed by removal of the glycosidic methyl groups, gave a tetramethyl fructose having a specific rotation in aqueous solution of +31.0 degrees. This agrees with that reported for tetramethylfructofuranose $\left([\alpha]_{\mathrm{D}}^{20}=+31.3^{\circ}\right.$, in water $)$ and excludes the pyranose derivative $\left([\alpha]_{\mathrm{D}}^{20}=-121.3^{\circ}\right.$, in water). By establishing the ring structure of the fructose residues, the only assumption made by McDonald and Jackson when they proposed the following for- 
mulas as the possible structures for difructose anhydride II has been removed:

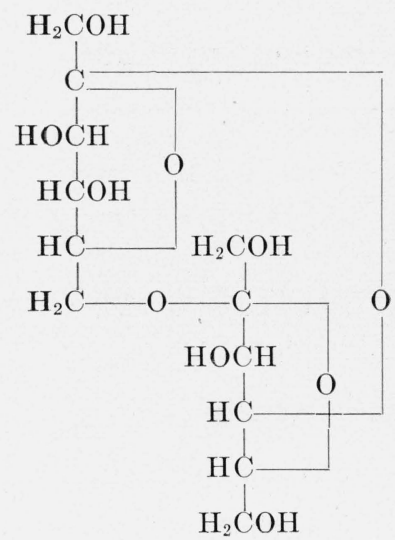

(1)

$2,4^{\prime}-6,2^{\prime}$-Difructofuranose

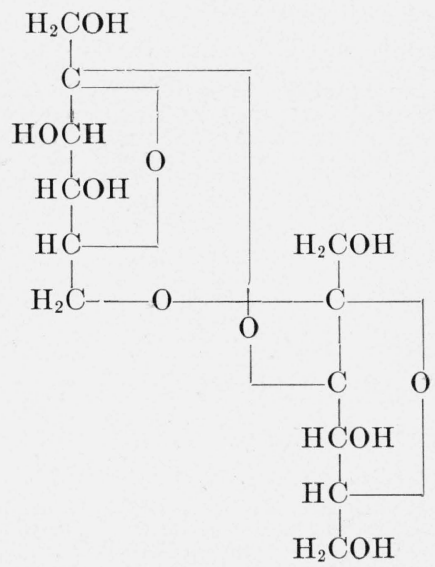

(2)

$2,3^{\prime}-6,2^{\prime}$-Difructofuranose<smiles>O=C(O)C1COC2(CC(CO)C(C(=O)O)C2O)O1</smiles>

(3)

$2,1^{\prime}-4,2^{\prime}$-Difructofuranose

The sugar whose structure is shown by (3) upon hydrolysis would yield 3,4,6- and 1,3,6trimethylfructose. Formulas (1) and (2) represent sugars whose hexamethyl derivatives on acid treatment would be converted to 1,3,4-trimethylfructose along with 1,3,6- or 1,4,6-trimethylfructose. Since the sugar of formula (3) is the only one in which methylation and hydrolysis would yield 3,4,6-trimethylfructose, identification of this substance as one of the hydrolysis products of the hexamethyl derivative would exclude all other possibilities and establish the structure of difructose anhydride II as $2,1^{\prime}-4,2^{\prime}$-difructofuranose.

As previously stated, McDonald and Jackson obtained an oil when the hydrolysis product of the hexamethyl derivative was reacted with phenylhydrazine. By a chromatographic process crystalline 3,4,6-trimethylglucosazone has been separated and identified as one of the constituents of this reaction product. The structure of difructose anhydride II is therefore established as $2,1^{\prime}-4,2^{\prime}$-difructofuranose (formula 3 ).

\section{Experimental Procedure}

\section{Purification of 3,4,6-Trimethylglucosazone}

3,4,6-Trimethylfructose and its phenylosazone were prepared from inulin according to the method of Haworth and Learner [7]. The osazone, which

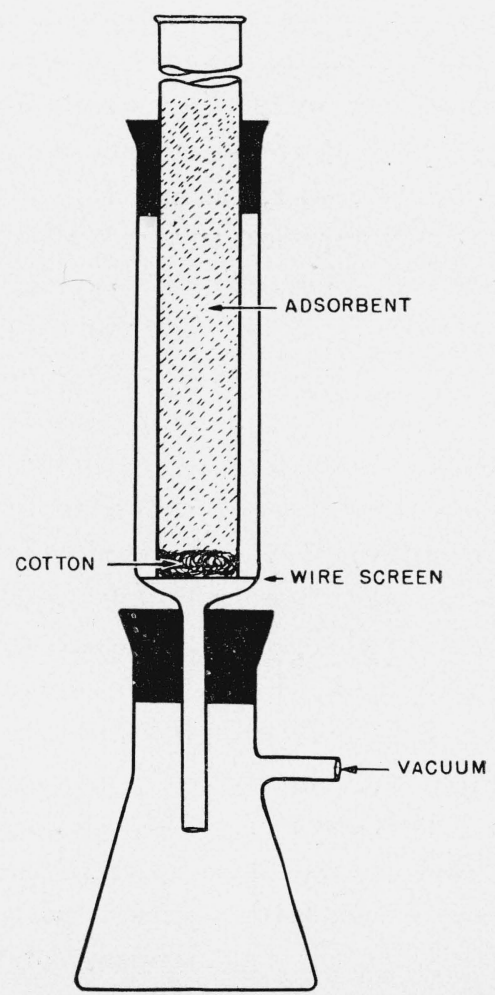

FiguRe 1.-Apparatus for chromatographic adsorption. 
separated as a dark-red oil from the reaction mixture, was washed with water and air-dried. Instead of following the procedure for crystallization, this viscous material was dissolved in carbon tetrachloride and purified by adsorption on a chromatographic column.

The adsorption column was prepared from Magnesol, ${ }^{2}$ using Celite as a filter aid in the proportion of 5 parts (by weight) of Magnesol to 1 part of Celite. A column about $17 \mathrm{~cm}$ in length was formed by packing $7 \mathrm{~g}$ of the mixture in a glass tube $11 \mathrm{~mm}$ in diameter, using suction. (See fig. 1.) Best results were obtained when the column was wet with pure solvent previous to the addition of the solution containing not more than $50 \mathrm{mg}$ of osazone. About $500 \mathrm{ml}$ of carbon tetrachloride was necessary to properly develop this chromatogram.

The column consisted of four distinct bands, the largest of which was the bright yellow area containing the glucosazone. This yellow band, about $8 \mathrm{~cm}$ in length, was preceded by a brown zone approximately one-fourth this length. An orange ring appeared immediately below the glucosazone and the lower portion of the column took on a pink color as the chromatogram was developed. It was noted that exposure to sunlight caused a surface discoloration, indicating decomposition. Hence in subsequent separations a paper covering was used to protect the column from light.

The yellow portion of the column was removed and the osazone extracted with alcohol. After evaporation the residue crystallized from an aqueous alcohol solution. The osazone was filtered and recrystallized several times from an ether-petroleum ether mixture, mp $138^{\circ} \mathrm{C}$ (uncorrected).

\section{3,4,6-Trimethylglucosazone from Difructose Anhydride II}

Five grams of hexamethyl difructose anhydride II was hydrolyzed at $95^{\circ} \mathrm{C}$ for 160 minutes in $0.8 N$ hydrochloric acid solution. The yellowish solution was neutralized with barium carbonate and evaporated to dryness in vacuum. The methylfructoses were extracted with chloroform the the solvent evaporated.

${ }^{2} \mathrm{~A}$ synthetic hydrated magnesium acid silicate $\left(2 \mathrm{MgO} .5 \mathrm{SiO}_{2}\right)$
The mixture of trimethylfructoses $(0.5 \mathrm{~g})$ was digested with $10 \mathrm{ml}$ of dilute acetic acid and 0.75 $\mathrm{g}$ of phenylhydrazine at $100^{\circ} \mathrm{C}$ for 20 minutes, at which time a large amount of a dark-red oil had separated. This oil was washed with water, and 50-mg portions, dissolved in carbon tetrachloride, were purified by means of an adsorption column containing Magnesol, as previously described.

The chromatogram contained the same large yellow area preceded by a brown zone and followed by an orange ring. There was an additional narrow red band at the top of the column, and at the bottom of the column a yellow zone formed, which was slowly eluted.

The portion containing the osazone was removed and extracted with alcohol. After evaporation of the solvent, the residue was taken up in carbon tetrachloride and added to another Magnesol column. A bright-yellow zone with a small amount of dark material at the top of the column resulted after approximately $300 \mathrm{ml}$ of carbon tetrachloride was passed through. The yellow band was extracted with ether and evaporated to a concentrated solution. Petroleum ether was added to a faint turbidity and in a short time crystals appeared. After repeated recrystallization from ether-petroleum ether, a melting point of $136^{\circ} \mathrm{C}$ (uncorrected) was obtained, which remained constant after further recrystallization. A mixture of this material and 3,4,6-trimethylglucosazone melted at $137^{\circ} \mathrm{C}$ (uncorrected).

\section{References}

[1] A. Pictet and J. Chavan, Helv. Chim. Acta 9, 807 (1926).

[2] R. F. Jackson and S. M. Goergen, BS J. Research 3, 27 (1929) RP79.

[3] R. F. Jackson and E. J. McDonald, BS J. Research 6, 709 (1931) RP299.

[4] W. N. Haworth and H. R. L. Streight, Helv. Chim. Acta 15, 693 (1932).

[5] E. J. McDonald and R. F. Jackson, J. Research NBS 24, 181 (1940) RP1277.

[6] E. J. McDonald and R. F. Jackson, J. Research NBS 35, 497 (1945) RP1683.

[7] W. N. Haworth and A. Learner, J. Chem. Soc. 1928, 619.

Washington, December 9, 1946. 